Chronic Obstructive Pulmonary Diseases: Journal of the COPD Foundation Original Research

\title{
High-Dose Versus Low-Dose Systemic Steroids in the Treatment of Acute Exacerbations of Chronic Obstructive Pulmonary Disease: Systematic Review
}

Diego Bonilla Arcos, $\mathrm{MD}^{1}$ Jerry A. Krishnan, $\mathrm{MD}, \mathrm{PhD}^{2} \mathrm{R}$. William Vandivier, $\mathrm{MD}^{3}$ Jonathan E. Sevransky, MD, MHS ${ }^{4}$ William Checkley, MD, $\mathrm{PhD}^{5}$ Tyree H. Kiser, PharmD ${ }^{6}$ Jamie L. Sullivan, $\mathrm{MPH}^{7}$ John W. Walsh, ${ }^{7}$ Robert A. Wise, $\mathrm{MD}^{5}$ and Kevin C. Wilson, MD ${ }^{1,8}$ for the DECIDE ${ }^{9}$ Investigators

\section{Abstract}

Background: Treatment of an acute exacerbation of chronic obstructive pulmonary disease (AECOPD) with systemic steroids reduces treatment failure, shortens hospital length of stay, improves lung function, and reduces dyspnea. However, it can also cause hyperglycemia, delirium, fluid retention, and other side effects. The balance of these desirable and undesirable effects probably varies according to the steroid dose.

Methods: We asked the question, "Should patients having an AECOPD receive low-dose or high-dose systemic steroids?" We searched Medline and the Cochran Central Register of Controlled Trials (CENTRAL) using a sensitive search strategy built around the medical subject heading, "COPD," and variations of the keywords exacerbation, steroids, and randomized trials. Our search yielded 1702 articles in Medline and 885 articles in CENTRAL; we reviewed the full text of 35 articles and selected 11 studies that met the following conditions: randomized trial, enrolled patients having an AECOPD, compared one systemic steroid regimen to another, measured clinical outcomes, and was published in a peer-reviewed journal.

Results: None of the selected trials directly compared the effects of different systemic steroid doses on clinical outcomes in patients with AECOPD. Four trials compared durations of steroid treatment, 3 trials compared types of steroids, 1 trial compared routes of steroid delivery, and 3 trials compared multiple variables.

Conclusion: There is a paucity of data to support the selection of a systemic steroid dose in patients having an AECOPD. Randomized trials that measure patient-centered outcomes and compare doses of systemic steroids in patients having an AECOPD are needed.

\footnotetext{
Abbreviations: acute exacerbation of chronic obstructive pulmonary disease, AECOPD; Cochrane Central Register of Controlled Trials, CENTRAL; chronic obstructive pulmonary disease, COPD; Grading, Recommendations, Assessment, Development, and Evaluation,

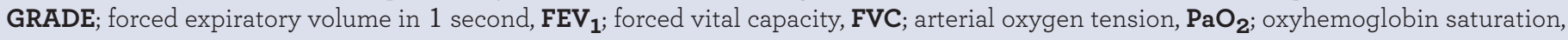
$\mathrm{SpO}_{2}$; oral, PO; intravenous, IV; every, q; every day, qD

Funding Support: Not Applicable.

Date of Acceptance: November 2, 2015

Citation: Arcos DB, Krishnan JA, William KR, et al. High-dose versus low-dose systemic steroids in the treatment of acute exacerbations of chronic obstructive pulmonary disease: A systematic review. Chronic Obstr Pulm Dis (Miami). 2016;3(2):580-588. doi: http://dx.doi. org/10.15326/jcopdf.3.2.2015.0178
}

1 The Pulmonary Center, Boston University School of Medicine, Massachusetts

2 University of Illinois Hospital \& Health Sciences System, Chicago
3 Division of Pulmonary Sciences and Critical Care Medicine, University of Colorado Denver Anschutz Medical Campus, Denver 
4 Division of Pulmonary and Critical Care Medicine, Emory
University, Atlanta, Georgia

5 Division of Pulmonary and Critical Care, School of Medicine, Johns Hopkins University, Baltimore, Maryland Department of Clinical Pharmacy, University of Colorado Denver Anschutz Medical Campus Denver

6 Department of Clinical Pharmacy, University of Colorado Denver Anschutz Medical Campus, Denver

7 COPD Foundation, Washington, D.C.

8 Documents and Patient Education Department, American Thoracic Society, New York, New York

9 DosE of CorticosteroIDs for Exacerbations of COPD (DECIDE)

\section{Address correspondence to:}

Kevin C. Wilson, M.D.

The Pulmonary Center

72 E. Concord Street, R-304

Boston, MA 02118

Email: kcwilson@bu.edu

\section{Keywords:}

chronic obstructive pulmonary disease; COPD; corticosteroids; exacerbation; dose

\section{Introduction}

Acute exacerbations of chronic obstructive pulmonary disease (AECOPD) are characterized by increased cough, sputum production, and dyspnea. They impair quality of life, frequently require urgent care or hospitalization, and increase the cost of care. ${ }^{1}$ Systemic steroids are a mainstay of AECOPD treatment. They reduce treatment failure, shorten hospital length of stay, improve lung function, and reduce dyspnea; however, they also cause hyperglycemia, delirium, fluid retention, and other side effects. ${ }^{2}$ The balance of these desirable and undesirable effects probably varies according to the steroid dose.

Observational studies suggest that low-doses of systemic steroids may be superior to high-doses in patients with AECOPD, ${ }^{2-4}$ even though high doses are more commonly used. ${ }^{5}$ In the most recent study, Kiser et al performed a retrospective cohort study that compared low-dose systemic steroids (defined as the equivalent of methylprednisolone $\leq 240 \mathrm{mg} /$ day) with high-dose systemic steroids (defined as the equivalent of methylprednisolone $>240 \mathrm{mg} /$ day) in 17,239 patients with an AECOPD. Participants who received low-doses of steroids had a shorter hospital stay, intensive care unit stay, duration of mechanical ventilation, and less frequent hyperglycemia requiring insulin and fungal infections. ${ }^{2}$ Lindenauer et al and Vondracek et al similarly performed retrospective cohort studies that favored low-dose systemic steroid therapy. ${ }^{3,4}$ While this observational evidence is suggestive, such studies are susceptible to bias due to unmeasured confounders. Therefore, randomized trials are necessary to confirm that the effects seen in the observational studies are, in fact, due to the intervention rather than confounders.

We performed a systematic review to search for randomized trials that addressed our question, "Should patients having an AECOPD receive low-dose or highdose systemic steroids?" The goal of the systematic review was to confirm that the optimal dose of systemic steroids in patients having a COPD exacerbation is a knowledge gap, as background for a future proposal to conduct a randomized controlled trial comparing highdose systemic steroids with low-dose systemic steroids in this population.

\section{Methods}

\section{Literature Search}

Two researchers (DBA, KCW) independently searched the MEDLINE database using the PubMed search engine and the Cochrane Central Register of Controlled Trials (CENTRAL) database. The sensitive search strategy was built around the medical subject heading, "COPD [mh]", and variations of keywords for exacerbation (i.e., exacerb*, acute*, status*, sever*, wors*, emergenc*, attack*, and crisis), steroids (i.e., "adrenal cortex hormone", steroid*, glucocorticoid*, corticoid*, corticosteroid*, beclomethasone, betamethasone, fluticasone, cortisone, dexamethasone, hydrocortisone, prednisolone, prednisone, methylprednisolone, sterapred, methylprednisone, and triamcinolone), and randomized controlled trials (i.e., randomized controlled trial, controlled clinical trial, random*, trial, and control*). The search was restricted to human studies, but there were were no restrictions on language, dates searched, or publication status.

\section{Study Selection}

Study selection criteria included the following: randomized trial, enrolled patients having an AECOPD, compared one systemic steroid regimen to another, measured clinical outcomes, and published in a peerreviewed journal. The decision to include trials that compared one systemic steroid regimen to another, rather than including only trials that compared one dose to another, was made to ensure that subgroup analyses 
comparing one dose to another would not be missed.

The researchers (DBA, KCW) independently screened the titles and abstracts, and then full text articles. Disagreements were resolved by discussion and consensus. Another researcher (WC) was designated as the final arbiter of disagreements that could not be resolved by discussion, but this was not necessary.

\section{Evidence Synthesis}

The research plan stipulated that data comparing one systemic steroid dose with another would be extracted from the selected studies and recorded on a data extraction sheet by one researcher (DBA) and then verified by another researcher (KCW). Two analyses were planned for each clinical outcome. The first was to categorize the systemic steroids as low-dose or high-dose and compare the effects on each clinical outcome; the second, if feasible, was to look for a doseresponse gradient by determining the effect of each systemic steroid dose on each outcome. The quality of evidence was then to be appraised using the Grading, Recommendations, Assessment, Development, and Evaluation (GRADE) approach. ${ }^{6}$ However, no randomized trials comparing one systemic steroid dose with another were identified and, therefore, the research plan was modified to a qualitative summary of the evidence comparing various systemic steroid regimens.

\section{Results}

The sensitive literature search of the MEDLINE database identified 1598 articles during an initial search done by KCW in the fall of 2014 and 1702 articles during a repeat search by DBA in the summer of 2015 (Table 1). A similar search of the CENTRAL database identified 827 articles during an initial search done by KCW in the fall of 2014 and 885 articles during a repeat search by DBA in the summer of 2015. The vast majority of articles were excluded by review of the title and abstract, leaving 35 articles for full text review. Among the articles that underwent full text review, 24 were excluded and 11 were selected. Reasons for exclusion included the article not being a randomized trial (e.g., a journal club; $\mathrm{n}=12$ ), the study being reported as an abstract but never published in a peer-reviewed journal $(n=6)$, the control group being something other than an alternative systemic steroid regimen (i.e., placebo or a non-steroid agent; $n=4$ ), and measurement of physiological rather than clinical outcomes $(\mathrm{n}=2)$ (Figure 1 ).
We did not identify any randomized trials that compared the effects of different systemic steroid doses on clinical outcomes in patients with AECOPD, either as a primary comparison or a subgroup analysis. The selected trials comparing one systemic steroid regimen with another in patients with AECOPD included 4 randomized trials that compared durations of systemic steroid treatment, 3 randomized trials that compared types of systemic steroids, 1 randomized trial that compared different routes of steroid delivery, and 3 randomized trials that compared multiple variables (Table 2).

\section{Duration of Steroid Treatment}

Four randomized trials compared different durations of systemic steroid treatment. ${ }^{7-10}$ The trials compared 3 days with 10 days, ${ }^{7} 5$ days with 14 days, ${ }^{8} 15$ days with 56 days, ${ }^{9}$ and 7 days with 14 days. ${ }^{10}$ Three trials ( $n=561$ patients) found no difference in the re-exacerbation rate, treatment failure rate, hospital length of stay, dyspnea, frequency of adverse events, or physiological measures (i.e., forced expiratory volume in 1 second $\left[\mathrm{FEV}_{1}\right]$, forced vital capacity [FVC], arterial oxygen tension $\left.\left[\mathrm{PaO}_{2}\right]\right) \cdot{ }^{8-10}$ In contrast, 1 trial ( $\mathrm{n}=34$ patients) found no difference in the re-exacerbation rate or incidence of hyperglycemia, but reported that a longer duration of systemic steroids conferred greater improvement in the $\mathrm{FEV}_{1}, \mathrm{FVC}, \mathrm{PaO}_{2}$, and dyspnea on exertion. ${ }^{7}$

\section{Type of Steroids}

Three trials randomly assigned patients with an AECOPD to methylprednisolone or an equivalent dose of hydrocortisone ( $\mathrm{n}=97$ patients), ${ }^{11}$ dexamethasone ( $\mathrm{n}=142$ patients), ${ }^{12}$ or a novel systemic steroid, deflazacort hemisuccinate ( $\mathrm{n}=60$ patients). ${ }^{13}$ Compared with methylprednisolone: patients who received hydrocortisone had no difference in the treatment failure rate, length of stay in the emergency department, or dyspnea, but had a lower $\mathrm{FEV}_{1}$, lower peak expiratory flow rate, and more hyperglycemia ${ }^{11}$; patients who received dexamethasone had no differences in $\mathrm{PaO}_{2}$, sputum culture, or adverse effects, but had less improvement in their $\mathrm{FEV}_{1}$, symptom score, and $\mathrm{SpO}_{2}$, as well as a longer duration to maximal effect ${ }^{12}$; and, patients who received deflazacort had similar $\mathrm{FEV}_{1}$ and peak expiratory flow measurements. ${ }^{13}$

\section{Route of Steroid Delivery}

One trial randomly assigned 210 patients with AECOPD 


\section{Table 1. Search Strategy and Search Results}

\section{Search Terms}

1 COPD [mh]

2 "adrenal cortex hormone*"

3 steroid*

4 glucocorticoid*

5 corticoid*

6 corticosteroid*

7 beclomethasone

8 betamethasone

9 fluticasone

10 cortisone

11 dexamethasone

12 hydrocortisone

13 prednisolone

14 prednisone

15 methylprednisolone

16 sterapred

17 methylprednisone

18 triamcinolone

19 \#2 OR \#3 OR \#4 OR \#5 OR \#6 OR \#7 OR \#8

OR \#9 OR \#10 OR \#11 OR \#12 OR \#13 OR

\#14 OR \#15 OR \#16 OR \#17 OR \#18

\begin{tabular}{l|r|r}
\hline 20 exacerb* & 65,879 & 69,654 \\
\hline 21 acute $^{*}$ & 977,143 & $1,010,859$ \\
\hline 22 status $^{*}$ & 725,314 & 760,385 \\
\hline 23 sever* & $1,068,592$ & $1,115,305$ \\
\hline 24 wors $^{*}$ & 145,414 & 154,577 \\
\hline 25 emergenc $^{*}$ & 314,151 & 332,254 \\
\hline 26 attack & 110,887 & 114,259 \\
\hline 27 crisis & 41,011 & 42,395 \\
\hline 28 \#20 OR \#21 OR \#22 OR \#23 OR \#24 OR \#25 & $2,974,552$ & $3,101,299$ \\
$\quad$ OR \#26 OR \#27 & & \\
\hline 29 randomized controlled trial [pt] & 373,048 & 387,884 \\
\hline 30 controlled clinical trial [pt] & 87,860 & 88,869 \\
\hline 31 random* [tiab] & 735,661 & 775,966 \\
\hline 32 trial [tiab] & 371,604 & 392,671 \\
\hline 33 control* [tiab] & $2,673,873$ & $2,792,091$ \\
\hline 34 humans [mh] & $13,425,917$ & $13,803,726$ \\
\hline 35 \#29 OR \#30 OR \#31 OR \#32 OR \#33 OR \#34 & $14,717,208$ & $15,160,678$ \\
\hline 36 \#1 AND \#19 AND \#28 AND \#35 & 1598 & 1702 \\
\hline & & \\
\hline
\end{tabular}

to receive intravenous or oral prednisolone at equivalent doses and durations. ${ }^{14}$ There were no differences in the treatment failure rate, length of hospital stay, FEV 1 , or health-related quality of life.

Reviewer \#1 Reviewer \#2 Sept 28, 2014 May 28, 2015

\begin{tabular}{|r|r}
\hline 36,252 & 38,116 \\
\hline 127 & 127 \\
\hline 187,694 & 284,738 \\
\hline 5519 & 193,313 \\
\hline 77,925 & 85,496 \\
\hline 3475 & 3549 \\
\hline 7372 & 7508 \\
\hline 3415 & 3536 \\
\hline 22,504 & 22,601 \\
\hline 58,726 & 60,055 \\
\hline 68,125 & 69,170 \\
\hline 53,481 & 54,566 \\
\hline 45,410 & 46,269 \\
\hline 21,333 & 21,874 \\
\hline 45,410 & 46,269 \\
\hline 218 & 223 \\
\hline 9648 & 9932 \\
\hline 562,973 & 576,970 \\
\hline
\end{tabular}

\section{Multiple Variables}

Three randomized trials compared multiple variables. ${ }^{1517}$ Two of the trials included the dose as one of the variables ${ }^{15,16}$; however, neither performed a subgroup analysis to compare the doses.

One randomized trial varied both the dose and route, randomly assigning 40 patients with AECOPD to receive methylprednisolone $32 \mathrm{mg}$ per day orally for 7 days or $1 \mathrm{mg} /$ $\mathrm{kg}$ per day intravenously for 4 days and then $0.5 \mathrm{mg} / \mathrm{kg}$ per day orally for 3 days. ${ }^{15}$ The groups had a similar length of hospital stay, treatment failure rate, re-exacerbation rate, rate of unplanned visits to the primary care physician or emergency department, and hospitalization rate. There were also similar improvements in the $\mathrm{FEV}_{1}, \mathrm{PaO}_{2}$, and dyspnea in both groups. More patients in the lowdose arm developed respiratory failure and died, but there were too few events to determine if the difference was real. There was a trend toward less hyperglycemia and less hypertension with the low dose regimen.

Another randomized trial varied the duration, route, and dose. The trial randomly assigned 37 patients with AECOPD to receive either methylprednisolone $40 \mathrm{mg}$ per day intravenously for 10 days 


\section{Figure 1. Flow of Information Diagram}

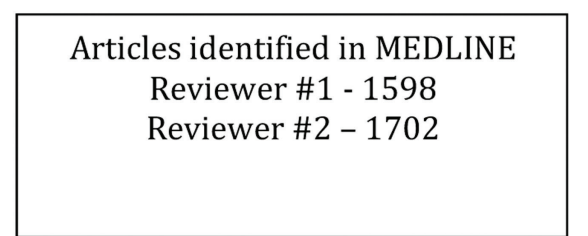

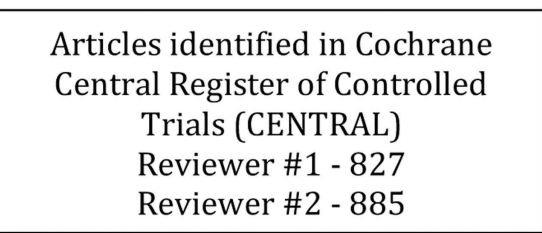



and then 20mg per day intravenously for 4 days, or alternatively a tapering dose of methylprednisolone orally for 46 days. ${ }^{16}$ There were no differences in dyspnea, health-related quality of life, patient satisfaction, length of hospital stay, readmission rate, $\mathrm{FEV}_{1}$, or FVC.

The third randomized trial varied the route of administration and co-interventions. Thirty-four patients with AECOPD were randomly assigned to receive methylprednisolone $40 \mathrm{mg}$ orally plus bronchodilators by meter dose inhaler or, alternatively, methylprednisolone 40mg intravenously plus nebulized bronchodilators. ${ }^{17}$ No differences were detected in the length of hospital stay, treatment failure rate, or FEV 1 .

\section{Discussion}

Systemic steroids administered to patients with AECOPD reduce treatment failure, shorten hospital length of stay, improve lung function, and reduce dyspnea. $^{2}$ However, observational evidence suggests that high-dose systemic steroids (i.e., the usual clinical practice ${ }^{5}$ ) are associated with worse clinical outcomes than low-dose systemic steroids. ${ }^{2-4}$ A potential explanation for this observation is that the undesirable effects of systemic steroids are probably more common or more severe when higher doses are used, including hyperglycemia, delirium, fluid retention, muscle weakness, infection, and other side effects.

Observational evidence may be misleading because results may be influenced by unmeasured confounders. Therefore, we sought randomized trials to answer our question, "Should patients having an AECOPD receive low-dose or high-dose systemic steroids?" Despite reviewing the titles, abstracts, and/or full text of roughly 2000 articles, we did not identify a single randomized trial that compared high-dose systemic steroids with low-dose systemic steroids in patients with AECOPD, or that provided enough data for us to perform our own 


\section{Table 2. Summary of Randomized Trials Comparing Systemic Steroid Regimens}

\begin{tabular}{|c|c|c|c|}
\hline $\begin{array}{l}\text { Study } \\
\text { Dose } \\
\text { No studies ic } \\
\text { Duration }\end{array}$ & $\begin{array}{l}\text { Intervention } \\
\text { lentified }\end{array}$ & Comparator & Key Findings \\
\hline $\begin{array}{l}\text { Niewoehner } \\
1999^{9}\end{array}$ & $\begin{array}{l}15 \text { days: Methylprednisolone } \\
125 \text { mg IV q6 hours on days } \\
1-3 \text {, then prednisolone PO } \\
\text { taper on days } 4-15 \text {, then } \\
\text { placebo on days } 16-56 ; n=80 \text {. }\end{array}$ & $\begin{array}{l}56 \text { days: Methylprednisolone } \\
125 \text { mg } I V \text { q6 hours on days } \\
1-3 \text {, then prednisolone PO } \\
\text { taper on days } 4-56 ; n=80 .\end{array}$ & $\begin{array}{l}\text { There were no differences in treatment } \\
\text { failure rate, hospital length of stay, } \\
\text { change in } \mathrm{FEV}_{1} \text {, or adverse events. An } \\
\text { exception was that serious secondary } \\
\text { infections were more common among } \\
\text { the long-duration group. }\end{array}$ \\
\hline $\begin{array}{l}\text { Sayiner } \\
2001^{7}\end{array}$ & $\begin{array}{l}3 \text { days: Methylprednisolone } \\
0.5 \mathrm{mg} / \mathrm{kg} \text { IV q6 hours on } \\
\text { days } 1-3, \text { then placebo IV } \\
\text { q12 hours on days } 4-6, \text { then } \\
\text { placebo IV qD on days } 7-10 ; \\
\mathrm{n}=17 .\end{array}$ & $\begin{array}{l}10 \text { days: Methylprednisolone } \\
0.5 \mathrm{mg} / \mathrm{kg} \text { IV q6 hours on days } \\
1-3, \text { then methylprednisolone } \\
0.5 \mathrm{mg} / \mathrm{kg} \text { IV q12 hours on } \\
\text { days } 4-6 \text {, then } \\
\text { methylprednisolone } 0.5 \mathrm{mg} / \\
\mathrm{kg} \text { IV qD on days } 7-10 ; \mathrm{n}=17 \text {. }\end{array}$ & $\begin{array}{l}\text { Longer duration steroids conferred } \\
\text { greater improvement in } \mathrm{FEV}_{1}, \mathrm{FVC}, \mathrm{PaO}_{2} \text {, } \\
\text { and dyspnea on exertion. There was no } \\
\text { difference in the re-exacerbation rate or } \\
\text { hyperglycemia. }\end{array}$ \\
\hline $\begin{array}{l}\text { Chen } \\
2008^{10}\end{array}$ & $\begin{array}{l}7 \text { days: Prednisolone } 30 \mathrm{mg} \\
\text { PO qD on days } 1-7 \text {, then } \\
\text { placebo } P O \mathrm{qD} \text { on days } 8-14 \text {; } \\
\mathrm{n}=44 \text {. }\end{array}$ & $\begin{array}{l}14 \text { days: Prednisolone } 30 \mathrm{mg} \\
\text { PO qD on days } 1-10 \text {, then } \\
\text { prednisolone } 15 \mathrm{mg} \text { PO qD on } \\
\text { days } 11-14 ; \mathrm{n}=43 .\end{array}$ & $\begin{array}{l}\text { There was no difference in the symptom } \\
\text { scores, treatment failure, re-exacerbation } \\
\text { rate, length of hospital stay, } \mathrm{FEV}_{1}, \mathrm{PaO}_{2} \text {, } \\
\text { or adverse effects. }\end{array}$ \\
\hline $\begin{array}{l}\text { Leuppi } \\
2013^{8}\end{array}$ & $\begin{array}{l}5 \text { days: Methylprednisolone } \\
\text { 40mg IV on day } 1, \text { then } \\
\text { prednisone } 40 \mathrm{mg} \text { PO on days } \\
2-5, \text { then placebo on days } \\
6-14 ; n=157 \text {. }\end{array}$ & $\begin{array}{l}14 \text { days: Methylprednisolone } \\
40 \mathrm{mg} \text { IV on day } 1 \text {, then } \\
\text { prednisone } 40 \mathrm{mg} \text { PO on days } \\
2-14 ; n=157 \text {. }\end{array}$ & $\begin{array}{l}\text { There was no difference in the time to } \\
\text { next exacerbation, re-exacerbation rate, } \\
\text { time to death, recovery of lung function, } \\
\text { or adverse reactions. }\end{array}$ \\
\hline
\end{tabular}

Steroid Type

$\begin{array}{lll}\text { Rizzato } & \text { Deflazacort: Deflazacort } & \text { Methylprednisolone: } \\ \text { 199813 } & \text { hemisuccinate 60 mg IV on } & \text { Methylprednisolone 40 mg IV } \\ & \text { days } 1-7 ; \mathrm{n}=30 . & \text { on days } 1-7 ; \mathrm{n}=30 .\end{array}$

Adverse effects were less frequent in the deflazacort group; however, the adverse effects noted were minor and not clearly drug-related. There was no difference in dyspnea, wheezing, use of accessory muscles, cyanosis, $\mathrm{FEV}_{1}, \mathrm{FVC}$, or peak expiratory flow rate.

\begin{tabular}{|c|c|c|}
\hline \multirow{8}{*}{$\begin{array}{l}\mathrm{Li} \\
2003^{12}\end{array}$} & Dexamethasone: & Methylprednisolone: \\
\hline & Dexamethasone $0.375 \mathrm{mg} / \mathrm{kg}$ & Methylprednisolone $2 \mathrm{mg} / \mathrm{kg}$ \\
\hline & IV qD on days 1 through $7-14$, & IV qD on days $1-3$, then \\
\hline & then changed to prednisone & reduced by $40 \mathrm{mg}$ every 3 \\
\hline & $30 \mathrm{mg}$ PO qD and reduced by & days. After 7-14 days of \\
\hline & 5 mg every 3 days until taking & methylprednisolone IV, \\
\hline & $5 \mathrm{mg}$ PO qD, then, switched to & switched to prednisone 30mg \\
\hline & ICS; $n=71$. & $\begin{array}{l}\mathrm{PO} \mathrm{qD} \text { and reduced by } 5 \mathrm{mg} \\
\text { every } 3 \text { days until taking } 5 \mathrm{mg} \\
\mathrm{PO} \mathrm{qD} \text {, then switched to } \mathrm{ICS} \text {; } \\
\mathrm{n}=71 \text {. }\end{array}$ \\
\hline
\end{tabular}

Methylprednisolone conferred greater benefit on $\mathrm{FEV}_{1}$, symptom score, $\mathrm{SpO}_{2}$, and time to maximal effect. There were no differences in $\mathrm{PaO}_{2}$, sputum culture, or adverse effects. 
Aggarwal

$2011^{11}$
Hydrocortisone:

Hydrocortisone 200 mg IV q6

hours until discharge, then

prednisolone $0.75 \mathrm{mg} / \mathrm{kg} \mathrm{PO}$

qD for 2 weeks; $\mathrm{n}=50$.
Methylprednisolone:

Methylprednisolone $125 \mathrm{mg}$

IV for one dose, then $40 \mathrm{mg}$ IV

q6 hours until discharge, then

methylprednisolone $0.6 \mathrm{mg} / \mathrm{kg}$

qD for 2 weeks; $\mathrm{n}=47$.
The methylprednisolone group had a better $\mathrm{FEV}_{1}$, better peak expiratory flow, and less hyperglycemia than the hydrocortisone group. There were no differences in the treatment failure components, length of ED stay, or dyspnea.

\section{Route}

De Jong Intravenous: Prednisolone
$2007^{14} \quad 60 \mathrm{mg}$ IV qD + placebo PO $\mathrm{qD}$ on days $1-5$, then switch to prednisolone $30 \mathrm{mg} \mathrm{PO}$ $\mathrm{qD}$ and begin tapering $5 \mathrm{mg}$ per day until either off or at prior maintenance dose; $\mathrm{n}=107$.
Oral: Prednisolone $60 \mathrm{mg}$ PO There were no differences in treatment $\mathrm{qD}+$ placebo IV qD on days 1-5, failure, length of stay, $\mathrm{FEV}_{1}$, or healththen switch to prednisolone $30 \mathrm{mg} \mathrm{PO} \mathrm{qD}$ and begin tapering $5 \mathrm{mg}$ per day until either off or at prior maintenance dose; $\mathrm{n}=103$. related quality of life.

\section{Multiple Variables}

\begin{tabular}{|c|c|c|c|}
\hline $\begin{array}{l}\text { Willaert } \\
2002^{16}\end{array}$ & $\begin{array}{l}\text { Methylprednisolone } 40 \mathrm{mg} \text { IV } \\
\mathrm{qD} \text { for days } 1-10 \text {, then } 20 \mathrm{mg} \\
\text { IV qD for days } 11-14 ; \mathrm{n}=19 .\end{array}$ & $\begin{array}{l}\text { Methylprednisolone } 32 \mathrm{mg} \text { PO } \\
\mathrm{qD} \text { for days } 1-7 \text {, then } 24 \mathrm{mg} \text { PO } \\
\mathrm{qD} \text { for days } 8-11 \text {, then decrease } \\
\text { by } 4 \text { mg PO qD every } 7 \text { days; } \\
\mathrm{n}=18 .\end{array}$ & $\begin{array}{l}\text { Three variables: duration, route, and dose. } \\
\text { There were no differences in dyspnea, } \\
\text { health-related quality of life, patient } \\
\text { satisfaction, length of hospital stay, } \\
\text { readmission rate, } \mathrm{FEV}_{1} \text {, or FVC. }\end{array}$ \\
\hline $\begin{array}{l}\text { Shortall } \\
2002^{17}\end{array}$ & $\begin{array}{l}\text { Methylprednisolone } 40 \mathrm{mg} \text { PO } \\
\mathrm{qD}+\text { MDI bronchodilators; } \\
\mathrm{n}=19 .\end{array}$ & $\begin{array}{l}\text { Methylprednisolone } 40 \mathrm{mg} \text { IV } \\
\mathrm{qD}+\text { nebulized bronchodilators; } \\
\mathrm{n}=15 .\end{array}$ & $\begin{array}{l}\text { Two variables: Route and co-intervention } \\
\text { (MDI vs. nebs). There were no differences } \\
\text { in the length of hospital stay, treatment } \\
\text { failure rate, or } \mathrm{FEV}_{1} \text {. }\end{array}$ \\
\hline $\begin{array}{l}\text { Cerviker } \\
2014\end{array}$ & $\begin{array}{l}\text { Methylprednisolone } 32 \mathrm{mg} / \\
\text { day PO for days } 1-7 ; \mathrm{n}=20 \text {. }\end{array}$ & $\begin{array}{l}\text { Methylprednisolone } 1.0 \mathrm{mg} / \mathrm{kg} \\
\text { IV qD for days } 1-4 \text {, then } 0.5 \mathrm{mg} / \\
\mathrm{kg} \text { IV qD for days } 5-7 ; \mathrm{n}=20 .\end{array}$ & $\begin{array}{l}\text { Two variables: dose and route. There was } \\
\text { no difference in the length of hospital stay, } \\
\text { treatment failure rate, re-exacerbation rate, } \\
\text { unplanned visits to primary care physician } \\
\text { or emergency department, or number of } \\
\text { hospitalizations. There were similar } \\
\text { improvements in } \mathrm{FEV}_{1}, \mathrm{PaO}_{2} \text {, and dyspnea } \\
\text { in both groups. }\end{array}$ \\
\hline
\end{tabular}

$\mathrm{PO}=$ oral; $\mathrm{IV}=$ intravenous; $\mathrm{n}=$ number; $\mathrm{q}=$ every; $\mathrm{qD}=$ every day; $\mathrm{FEV}_{1}=$ forced expiratory volume in 1 second; $\mathrm{FVC}=$ forced vital capacity; $\mathrm{PaO}_{2}=$ arterial oxygen tension; $\mathrm{SpO}_{2}=$ oxygen saturation measured by pulse oximetry; $\mathrm{MDI}=$ metered-dose inhaler.

analysis. Therefore, a critical knowledge gap exists and randomized trials comparing high-dose with lowdose systemic steroids in patients with AECOPD are urgently needed.

While we did not find any trials evaluating the dosing of systemic steroids, we did identify multiple trials that compared different durations, types, and routes of systemic steroid therapy, as well as trials comparing multiple variables. Overall, it appeared that short durations of systemic steroids were as effective as longer durations on most clinical outcomes. ${ }^{7-10}$ There was no evidence that alternative steroid types were superior to methylprednisolone ${ }^{11-13}$ and oral steroids appeared as effective as intravenous steroids. ${ }^{14}$

The major limitation of our study is the high rate at which new studies related to the treatment of AECOPD are being published, as indicated by the observation that more than 100 potentially relevant articles were published between our first literature search in the fall of 2014 and our repeat literature in the summer of 2015. Thus, it is possible, that a relevant study will be published between the completion of our literature search in the summer of 2015 and publication of this systematic review. In addition, neither foreign language 
databases nor allied health databases were searched; therefore, the possibility that a relevant study was not detected cannot be excluded. Finally, we did not reach out to the authors of the trials that varied multiple variables, including dose, to obtain the raw data and perform our own subgroup analysis comparing doses.

\section{Conclusion}

Our systematic review failed to identify any randomized trials comparing different doses of systemic corticosteroids for patients with AECOPD. Observational studies suggest higher doses are associated with the potential for adverse effects, but such analyses do not provide strong evidence due to the potential for unmeasured confounding or bias. Randomized controlled trials that measure patientcentered outcomes are needed to support the choice of systemic steroid dose in patients with AECOPD.

\section{Declaration of Interest}

$\mathrm{DBA}$ and KCW have an interest in evidence synthesis. JAK is a member of the COPD Foundation's Medical and Scientific Advisory Committee, is on the Advisory Board of the COPD Foundation's PRAXIS (Prevent and Reduce COPD Admissions through eXpertise and Innovation Sharing) initiative, and is the principle investigator of multiple COPD-related studies funded by the Patient-Centered Outcomes Research Institute and the National Heart Lung and Blood Institute. RWV is Director of the University of Colorado's COPD Center and has published both a large observational study and a review article on the same topic as this manuscript. JES was a founding member of the United States Critical Illness and Injury Trials Group and participates in critical care-related clinical trials. WC has research interests in epidemiology, COPD, and critical care. THK is a clinical pharmacist with an interest in dosing optimization in the intensive care unit. He has published both a large observational study and a review article on the same topic as this manuscript. JWW is President and Co-founder of the COPD Foundation. JLS is Director of Public Policy and Advocacy for the COPD Foundation. RAW is Chair of the COPD Foundation's Medical and Scientific Advisory Committee. He has participated as a clinical center principle investigator, steering committee member, coordinating center investigator, or chair for many of the major COPD clinical trials or cohorts over the past 20 years. 


\section{References}

1. Celli B, Decramer M, Wedzicha JA, et al. An official American Thoracic Society/European Respiratory Society statement: research questions in chronic obstructive pulmonary disease. Am J Respir Crit Care Med. 2015; 191(7):e4-e27. doi: http://dx.doi.org/10.1164/rccm.201501-0044ST

2. Kiser TH, Allen RR, Valuck RJ, Moss M, Vandivier RW. Outcomes associated with corticosteroid dosage in critically ill patients with acute exacerbations of chronic obstructive pulmonary disease. Am J Respir Crit Care Med. 2014; 189(9):1052-1064. doi: http://dx.doi.org/10.1164/rccm.201401-00580C

3. Lindenauer PK, Pekow PS, Lahti MC, Lee Y, Benjamin EM, Rothberg MD. Association of corticosteroid dose and route of administration with risk of treatment failure in acute exacerbation of chronic obstructive pulmonary disease. JAMA. 2010; 303(23):2359-2367. doi: http://dx.doi.org/10.1001/ jama.2010.796

4. Vondracek SF, Hemstreet BA. Retrospective evaluation of systemic corticosteroids for the management of acute exacerbations of chronic obstructive pulmonary disease. Am J Health Syst Pharm. 2006; 63(7):645-652. doi: http://dx.doi.org/10.2146/ajhp050316

5. Kiser TH, Sevransky JE, Krishnan JA, et al. Corticosteroid dosing for acute exacerbations of chronic obstructive pulmonary disease requiring ventilatory support [Abstract]. Am J Respir Crit Care Med. 2015; 191:A2540.

6. Balshem $\mathrm{H}$, Helfand $\mathrm{M}$, Schunemann HJ, et al. GRADE guidelines: 3. Rating the quality of evidence. J Clin Epidemiol. 2011; 64:401406. doi: http://dx.doi.org/10.1016/j.jclinepi.2010.07.015

7. Sayiner A, Aytemur ZA, Cirit M, Unsal I. Systemic glucocorticoids in severe exacerbations of COPD. CHEST. 2001; 119(3):726730. doi: http://dx.doi.org/10.1378/chest.119.3.726

8. Leuppi JD, Schuetz P, Bingisser R, et al. Short-term vs conventional glucocorticoid therapy in acute exacerbations of chronic obstructive pulmonary disease: the REDUCE randomized clinical trial. JAMA. 2013; 309(21):2223-2231. doi: http://dx.doi.org/10.1001/jama.2013.5023

9. Niewoehner DE, Erbland ML, Deupree RH, et al for the Department of Veterans Affairs Cooperative Study Group. Effect of systemic glucocorticoids on exacerbations of chronic obstructive pulmonary disease. N Engl J Med. 1999; 340:19411947. doi: http://dx.doi.org/10.1056/NEJM199906243402502

10. Chen G, Xie CM, Luo YF. The effects and therapeutic duration of oral corticosteroids in patients with acute exacerbation of chronic obstructive pulmonary diseases [in Chinese]. Chinese Journal of Tuberculosis and Respiratory Diseases. 2008; 31(8):577-580.

11. Aggarwal P, Wig N, Bhoi S. Efficacy of two corticosteroid regimens in acute exacerbation of chronic obstructive pulmonary disease. Int $J$ Tuberc Lung Dis. 2011; 15(5):687-692. doi: http://dx.doi.org/10.5588/ijtld.10.0540

12. Li H, He G, Chu H, Zhao L, Yu H. A step-wise application of methylprednisolone versus dexamethasone in the treatment of acute exacerbations of COPD. Respirology. 2003; 8(2):199-204. doi: http://dx.doi.org/10.1046/j.1440-1843.2003.00468.x
13. Rizzato G. Effects of deflazacort hemisuccinate versus methylprednisolone succinate in COPD exacerbations. Internista. 1998; 6(1):3540.

14. de Jong YP, Uil SM, Grotjohan HP, Postma DS, Kerstjens HA, van den Berg JW. Oral or IV prednisolone in the treatment of COPD exacerbations: A randomized, controlled, doubleblind study. CHEST. 2007; 132(6):1741-1747. doi: http://dx.doi.org/10.1378/chest.07-0208

15. Ceviker Y, Sayiner A. Comparison of two systemic steroid regimens for the treatment of COPD exacerbations. PulmPharmacol Ther. 2014; 27(2):179-183. doi: http://dx.doi.org/10.1016/j.pupt.2013.03.004

16. Willaert W, Daenen M, Bomans P, Verleden G, Decramer M. What is the optimal treatment strategy for chronic obstructive pulmonary disease exacerbations? Eur Respir J. 2002; 19:928-935. doi: http://dx.doi.org/10.1183/09031936.02.00268702

17. Shortall SP, Blum J, Oldenburg FA, Rodgerson L, Branscombe JM, Harrow EM. Treatment of patients hospitalized for exacerbations of chronic obstructive pulmonary disease: comparison of an oral/metered-dose inhaler regimen and an intravenous/nebulizer regimen. Respir Care. 2002; 47(2):154158. 